\title{
Ethanol and Isopropyl Alcohol Exposure Increases Biofilm Formation in Staphylococcus aureus and Staphylococcus epidermidis
}

\author{
Megan K. Luther · Sarah Bilida · Leonard A. Mermel · Kerry L. LaPlante
}

To view enhanced content go to www.infectiousdiseases-open.com

Received: February 25, 2015 / Published online: May 3, 2015

(C) The Author(s) 2015. This article is published with open access at Springerlink.com

\section{ABSTRACT}

Introduction: Alcohols, including ethanol and isopropyl alcohol, are used in clinical practice for disinfection and infection prevention. Recent studies, however, demonstrate that alcohols may enhance biofilm production in Staphylococci.

Methods: We quantified biofilm formation in the presence of ethanol and isopropyl alcohol

Electronic supplementary material The online version of this article (doi:10.1007/s40121-015-0065-y) contains supplementary material, which is available to authorized users.

M. K. Luther · L. A. Mermel · K. L. LaPlante ( $\square)$ Department of Pharmacy Practice, University of Rhode Island, 7 Greenhouse Road, Kingston, RI 02881, USA

e-mail: kerrylaplante@uri.edu

M. K. Luther · K. L. LaPlante

Rhode Island Infectious Diseases (RIID) Research Program Laboratory, Veterans Affairs Medical

Center, Providence, RI, USA

S. Bilida

Rhode Island College, Providence, RI, USA

L. A. Mermel · K. L. LaPlante

Warren Alpert Medical School of Brown University, Providence, RI, USA

L. A. Mermel

Rhode Island Hospital, Providence, RI, USA in six different, well-characterized strains of Staphylococcus epidermidis and Staphylococcus aureus. After $24 \mathrm{~h}$ of biofilm development, each strain was exposed to normal saline (NS), ethanol, or isopropyl alcohol (40\%, 60\%, 80\% and 95\%) for additional $24 \mathrm{~h}$ incubation. Adherent biofilms were stained and optical density was determined. Viability of strains was also determined after alcohol exposure.

Results: Ethanol increased biofilm formation in all six strains compared to normal saline $(p<0.05)$. There was increased biofilm formation with increasing ethanol concentration. Isopropyl alcohol also increased biofilm formation with increasing alcohol concentration in all six strains $(p<0.01$ vs NS). The slime-negative, chemical mutant strain of $S$. epidermidis increased biofilm formation after exposure to both alcohols, likely reverting back its primary phenotype through modulation of the intercellular adhesin repressor. All strains demonstrated viability after exposure to each alcohol concentration, though viability was decreased. Conclusion: Ethanol and isopropyl alcohol exposure increases biofilm formation of $S$. aureus and $S$. epidermidis at concentrations 
used in clinical settings. Ethanol and isopropyl alcohol did not eradicate viable Staphylococci from formed biofilm.

Keywords: Alcohol; Biofilm; Ethyl alcohol; Isopropanol; Staphylococcus aureus; Staphylococcus epidermidis

\section{INTRODUCTION}

Staphylococci, including Staphylococcus epidermidis and Staphylococcus aureus, are common biofilm-forming pathogens [1]. They frequently cause implant and catheterassociated infections, and are a significant cause of morbidity and mortality [1]. Previous studies have demonstrated increased biofilm production of $S$. epidermidis and $S$. aureus after exposure to different alcohols, including ethanol at concentrations above $40 \%[2,3]$. This is important since isopropyl alcohol is commonly used as a cutaneous disinfectant and ethanol is used in catheter lock solutions for the treatment and prevention of catheter-related bloodstream infections (CRBSI) [1, 4]. Although ethanol-based catheter lock solutions, including combinations with isopropyl alcohol, have been advocated for the prevention and management of CRBSI at concentrations between $25 \%$ and 100\%, ethanol-based lock solutions may have unintended consequences since CRBSI are frequently caused by biofilmforming bacteria [5, 6]. Additionally, ethanol use in lock solutions has been demonstrated to have other deleterious effects $[5,6]$.

We compared the effects of ethanol and isopropyl alcohol on Staphylococcal biofilms using a semi-quantitative microtiter plate assay to better understand the effect of these alcohols on biofilm formation. We also measured the viability of biofilm-embedded bacteria after exposure to ethanol or isopropyl alcohol.

\section{MATERIALS AND METHODS}

\section{Bacterial Strains}

Five ATCC Staphylococcal strains were evaluated: a biofilm-producing $S$. epidermidis strain (ATCC 35984; RP62A [ATCC ${ }^{\circledR}$, Manassas, Virginia]) and its isogenic, slime-negative, biofilm-deficient mutant derived from chemical mutagenesis (M7), two biofilm-forming methicillinsusceptible $S$. aureus strains (ATCC 35556 and ATCC 29213) and a biofilm-forming methicillin-resistant $S$. aureus strain (MRSA; ATCC 43300) [7-10]. ATCC 35984, ATCC 43300, and ATCC 29213 were originally isolated from clinical sources, including a catheter sepsis (ATCC 35984). Additionally, one known biofilm-forming clinical MRSA strain (L32; from blood at the Providence Veterans Affairs Medical Center) was tested [11].

\section{Agents tested}

Ethanol (Pharmco-aaper, Brookfield, CT, USA) and isopropyl alcohol (Acros, New Jersey, USA) were evaluated at concentrations of $40 \%, 60 \%$, $80 \%$, and $95 \%$ in sterile water for $24 \mathrm{~h}$ exposure. Normal saline (NS) was used for comparison.

\section{Medium}

Strains were grown overnight on Tryptic Soy Agar (TSA, Becton-Dickinson, Sparks, MD, USA). Supplemented Tryptic Soy Broth (STSB; Becton-Dickinson, Sparks, MD, USA) with $1 \%$ glucose, $2 \%$ sodium chloride, $25 \mathrm{mg} / \mathrm{L}$ calcium, and $12.5 \mathrm{mg} / \mathrm{L}$ magnesium was used to optimize biofilm production in the biofilm assay $[12,13]$. 


\section{Biofilm Formation Assay}

Quantification of biofilm formation was conducted using the microtiter plate assay first described by Christensen et al. [14] and modified as described [8, 11-13]. Briefly, a 0.5 McFarland standard of overnight growth of test strains was diluted into STSB. Inocula ( $6.5 \log _{10} \mathrm{CFU} / \mathrm{mL}$ ) were verified by plating. The inoculated medium was dispensed into wells of sterile flat-bottom 96-well polystyrene tissue culture plates (Costar no. 3596; Corning Inc., Corning, NY, USA). Plates were incubated statically at $37^{\circ} \mathrm{C}$. After $24 \mathrm{~h}$ of biofilm development, broth was removed and replaced with test solution and incubated at $37^{\circ} \mathrm{C}$ for an additional $24 \mathrm{~h}$. The solution was then removed and the plates were carefully rinsed three times with NS to remove planktonic bacteria. Adherent bacteria were dried overnight and stained with $2 \%$ crystal violet solution (Becton-Dickinson, Sparks, MD, USA). The crystal violet was then resolubilized in 95\% ethanol and the optical density (OD) of stained adherent bacterial films was read at $570 \mathrm{~nm}$ using a SpectraMax M2 Spectrophotometer (Molecular Devices, Sunnyvale, CA, USA).

\section{Viability}

Viability of biofilm-embedded Staphylococci was evaluated using a similar 96 well plate assay [15]. After inoculation, incubation and alcohol or NS exposure as above, media was removed and wells were carefully rinsed three times with NS to remove planktonic bacteria. Wells were then filled with $200 \mu \mathrm{L}$ of NS and plates were sonicated for $20 \mathrm{~min}$ in a water bath sonicator (Fisher Scientific FS20, Pittsburg, PA, USA) to disperse adherent biofilms. Viability was determined in quadruplicate on two occasions by plating aliquots from each strain and alcohol concentration. Plate counts were determined after $24 \mathrm{~h}$ incubation. The lower limit of detection for this method is $2.0 \log _{10} \mathrm{CFU} / \mathrm{mL}$.

\section{Statistical Analysis}

$\mathrm{OD}$ and $\log \mathrm{CFU} / \mathrm{mL}$ were compared between groups using analysis of variance (ANOVA) with Tukey's post hoc test [16]. Data is presented as the mean OD with standard error of the mean using at least eight replicates for each strain and test solution combination. Statistical analysis was conducted using SPSS (release 20; SPSS, Inc. Chicago, IL). A $p$ value of $<0.05$ was considered significant. Each alcohol concentration was compared to NS, and mean difference (change) in OD between alcohol and NS was determined, with a corresponding $p$ value. Mean differences in OD are presented as a range for all the strains in the results.

\section{Compliance with Ethics}

This article does not contain any new studies with human or animal subjects performed by any of the authors.

\section{RESULTS}

Ethanol exposure increased biofilm in all strains (Fig. 1a). In five strains, the amount of biofilm increased with increasing ethanol concentration. At $60 \%, 80 \%$ or $95 \%$ ethanol, more biofilm was produced than after exposure to NS (mean difference in OD vs NS $0.25-1.23$, $p<0.02$ ). One strain, the prolific biofilmforming $S$. epidermidis ATCC 35984, demonstrated the inverse trend of decreased biofilm production with higher ethanol concentration, which was significantly 

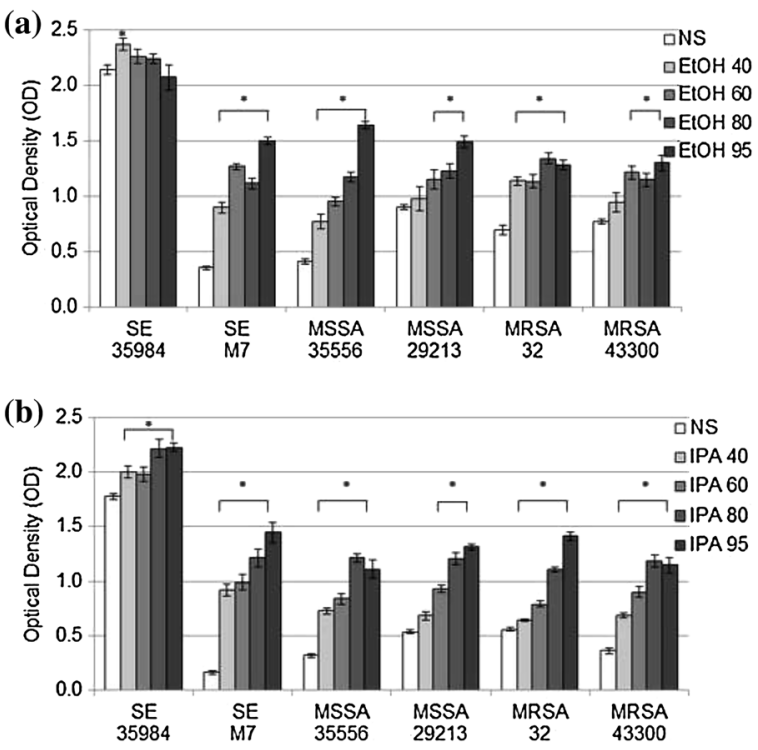

Fig. 1 Biofilm production after ethanol (a) or Isopropyl Alcohol (b) exposure for $24 \mathrm{~h}$. Mean \pm SEM optical density (OD) at $570 \mathrm{~nm}$ of stained biofilms in 96 well plates after $24 \mathrm{~h}$ exposure to $40 \%, 60 \%, 80 \%$, and $95 \%$ alcohols compared to normal saline $0.9 \%$ (NS) $(n=8$ each). SE 35984 S. epidermidis ATCC 35984, SE M7 S. epidermidis M7, MSSA 35556 methicillin-susceptible $S$. aureus ATCC 35556, MSSA 29213 methicillin-susceptible S. aureus ATCC 29213, MRSA 32 methicillin-resistant $S$. aureus clinical strain L32, MRSA 43300 methicillinresistant $S$. aureus ATCC 43300, EtOH ethanol, SEM standard error of the mean. (Asterisk) Statistically significant compared to NS $(p<0.05)$. SE $35984 p=0.04$; SE M7 $p<0.01$; MSSA $35556 p<0.01$; MSSA 29213 $p<0.02$; MRSA $32 p<0.01$; MRSA $43300 p<0.01$. IPA isopropyl alcohol. (Asterisk) Statistically significant compared to NS $(p<0.01$ for all $)$

different between $40 \%$ and $95 \%$ ethanol $(-0.29$, 95\% CI $0.03-0.55, \quad p<0.02)$. However, differences between other concentrations were not statistically significant. Isopropyl alcohol exposure (Fig. 1b) led to increased biofilm in all strains tested, with higher biofilm production for $60 \%, 80 \%$, and $95 \%$ alcohol compared to NS (mean difference in OD vs NS 0.15-1.28, $p<0.01)$.

Viable bacteria remained at all concentrations of both ethanol and isopropyl alcohol with a range up to $2.93 \log _{10} \mathrm{CFU} / \mathrm{mL}$ after ethanol exposure and $3.01 \log _{10} \mathrm{CFU} / \mathrm{mL}$ after isopropyl alcohol exposure. NS exposure yielded 2.35-4.4 $\log _{10} \mathrm{CFU} / \mathrm{mL}$, depending on strain. For S. epidermidis ATCC 35984 and M7, the quantity of viable bacteria was reduced by all of the alcohol conditions tested $(p<0.03)$. Cell counts were not significantly reduced by alcohol exposure for any of the $S$. aureus strains tested. For all strains, viable cell count tended to decrease with increasing alcohol concentration, but these differences were not statistically significant. Some bacterial counts $(\mathrm{CFU} / \mathrm{mL})$ reached the $2.0 \log _{10} \mathrm{CFU} / \mathrm{mL}$ lower limit of detection, but viable bacteria were present for each strain-alcohol concentration combination tested.

\section{DISCUSSION}

Our results are similar to a previous study demonstrating increased $S$. aureus biofilm formation after ethanol exposure [2], however, there are conflicting reports on the viability of those biofilm bacteria $[17,18]$. We found these bacteria within biofilm were viable, although viability was decreased compared to NS-exposed biofilm. In contrast to previous reports [4, 19], bacteria in biofilm were not eradicated after alcohol exposure. This may be due to different methods used to remove the biofilm from 96 well plates, as prior studies removed biofilm using cotton swabs [4, 19], whereas we sonicated the well plates.

We also found an increase in biofilm formation with increasing alcohol concentration. Only one strain, the prolific biofilm-forming $S$. epidermidis, decreased biofilm formation with increasing concentrations of ethanol. This strain was likely near maximal biofilm production possible in this assay. Small variations in 
biofilm formation are possible, as demonstrated by the differences in NS-exposed biofilm between the ethanol and isopropyl alcohol experiments. The differences in biofilm comparing other ethanol concentrations, such as $40 \%$ and $80 \%$ or $60 \%$ and $80 \%$ are not statistically significant for this strain.

The bactericidal effect of alcohol depends upon dehydration and denaturation of proteins [20]. Mixtures of alcohols and water (60-90\% $\mathrm{v} / \mathrm{v}$ ) are more effective because proteins are denatured more quickly in the presence of water $[20,21]$. Ethanol also causes leakage of the plasma membrane, disrupting bacterial growth and metabolism [22]. The impact of dehydration on cell death in the presence of alcohols may not be observed in catheter lock solutions since these do not dry, however denatured proteins and leaking membranes may still lead to decreased viability. The high concentrations of ethanol in catheter lock solutions increase biofilm formation in Staphylococci and also predisposes to catheter dysfunction and plasma protein precipitation [6].

Staphylococcus epidermidis M7, the isogenic slime-negative, biofilm-deficient mutant of $S$. epidermidis ATCC 35984 demonstrated increased OD with exposure to both alcohols; however, they were not as dense as the prolific biofilms of ATCC 35984. M7 was derived from ATCC 35984 through mitomycin C-induced mutations. M7, sometimes referred to as an accumulation-negative mutant, is distinguished from ATCC 35984 because it lacks a $140 \mathrm{kDa}$ antigen called accumulation-associated protein, but it has been found to have a $200 \mathrm{kDa}$ protein with similar homology $[23,24]$. This strain does not accumulate on glass and polystyrene surfaces [23], but it accumulates on polyvinyl chloride disks and has been shown to produce biofilm [25-28]. The exact mechanism for the mutation is unknown but is believed to be due to alteration of the intercellular adhesin (ica) gene [10]. The ica gene regulates production of polysaccharide intercellular adhesin, the major exopolysaccharide produced in $S$. epidermidis and $S$. aureus biofilm [29]. Ethanol increases Staphylococcal biofilm formation by increasing ica expression through modulation of the repressor, icaR $[2,3,29,30]$. It is possible that alcohol exposure and subsequent increase in ica expression allowed accumulation and biofilm formation of this strain in polystyrene plates. To our knowledge, this is the first report of any alcohol exposure to cause the M7 strain to increase biofilm formation.

Regarding limitations, we tested a small number of strains, including one clinical isolate which may have different biofilmforming behavior. The crystal violet used in this study stains cells and does not differentiate between viable and nonviable cells or quantify extracellular matrix production. Also, we did not characterize the composition or matrix production of the biofilms. We considered that alcohol may denature bacteria in biofilm, allowing for greater penetration of the crystal violet. However, differences in biofilm formation could be observed between wells even before the crystal violet stain was added. This also would not account for the increase in ica expression noted previously [30]. Viability may be underestimated using this method, since some adherent cells were visible in the bottom of wells after $20 \mathrm{~min}$ of sonication, particularly the prolific biofilm-forming ATCC 35984. Sonication of well plates can fail to release cells completely [31]. There was also a tendency for the number of bacteria to be higher in the center of the well plate than along the edges where evaporation was higher, further suggesting that dehydration played a role in cell viability. 


\section{CONCLUSION}

Staphylococci exposed to clinically relevant concentrations of ethanol and isopropyl alcohol increase biofilm formation; however, the viability of these biofilm-embedded bacteria was diminished. Future research should determine the impact of these findings on the use of various alcohol preparations in the management and prevention of infections due to biofilm-forming Staphylococci.

\section{ACKNOWLEDGMENTS}

We gratefully acknowledge Kayla Babcock and Katie Daffinee for laboratory assistance. Research reported in this publication was supported by an Institutional Development Award (IDeA) from the National Institute of General Medical Sciences of the National Institutes of Health under grant number 2P20GM103430 through Rhode Island IDeA Network for Excellence in Biomedical Research. All named authors meet the International Committee of Medical Journal Editors (ICMJE) criteria for authorship for this manuscript, take responsibility for the integrity of the work as a whole, and have given final approval to the version to be published. The views expressed are those of the authors and do not necessarily represent the position or policy of the United States Department of Veterans Affairs.

Conflict of interest. Megan Luther declares research funding from Pfizer and Cubist. Sarah Bilida declares no conflict of interest. Leonard Mermel declares Theravance, Astellas, CareFusion, Fresenius Medical, Marvao Medical research funding and/or consultancy. Kerry LaPlante declares Cubist, Astellas, Theravance, Forest, Davol, Marvao Medical, and Pfizer research funding, advisor, and/or consultancy.
Compliance with ethics guidelines. This article does not contain any new studies with human or animal subjects performed by any of the authors.

Open Access. This article is distributed under the terms of the Creative Commons Attribution Noncommercial License which permits any noncommercial use, distribution, and reproduction in any medium, provided the original author(s) and the source are credited.

\section{REFERENCES}

1. Mermel LA, Allon M, Bouza E, et al. Clinical practice guidelines for the diagnosis and management of intravascular catheter-related infection: 2009 Update by the Infectious Diseases Society of America. Clin Infect Dis. 2009;49(1):1-45. Erratum in: Clin Infect Dis. 2010 Apr 1;50(7):1079. Dosage error in article text. Clin Infect Dis. 2010 Feb 1;50(3):457.

2. Redelman CV, Maduakolam C, Anderson GG. Alcohol treatment enhances Staphylococcus aureus biofilm development. FEMS Immunol Med Microbiol. 2012;66(3):411-8.

3. Milisavljevic V, Tran LP, Batmalle C, Bootsma HJ. Benzyl alcohol and ethanol can enhance the pathogenic potential of clinical Staphylococcus epidermidis strains. Am J Infect Control. 2008;36(8):552-8.

4. Qu Y, Istivan TS, Daley AJ, Rouch DA, Deighton MA. Comparison of various antimicrobial agents as catheter lock solutions: preference for ethanol in eradication of coagulase-negative staphylococcal biofilms. J Med Microbiol. 2009;58(Pt 4):442-50.

5. Restrepo D, Laconi NS, Alcantar NA, et al. Inhibition of heparin precipitation, bacterial growth, and fungal growth with a combined isopropanol-ethanol locking solution for vascular access devices. J Pediatr Surg. 2015;50(3):472-7.

6. Mermel LA, Alang N. Adverse effects associated with ethanol catheter lock solutions: a systematic review. J Antimicrob Chemother. 2014;69(10):2611-9.

7. Ceri H, Olson ME, Stremick C, Read RR, Morck D, Buret A. The Calgary Biofilm Device: new technology for rapid determination of antibiotic 
susceptibilities of bacterial biofilms. J Clin Microbiol. 1999;37(6):1771-6.

8. Luther MK, Mermel LA, LaPlante KL. Comparison of ML8-X10 (a prototype oil-in-water microemulsion based on a novel free fatty acid), taurolidine/citrate/heparin and vancomycin/ heparin antimicrobial lock solutions in the eradication of biofilm-producing staphylococci from central venous catheters. J Antimicrob Chemother. 2014;69(12):3263-7.

9. Polonio RE, Mermel LA, Paquette GE, Sperry JF. Eradication of biofilm-forming Staphylococcus epidermidis (RP62A) by a combination of sodium salicylate and vancomycin. Antimicrob Agents Chemother. 2001;45(11):3262-6.

10. Schumacher-Perdreau F, Heilmann C, Peters G, Gotz F, Pulverer G. Comparative analysis of a biofilm-forming Staphylococcus epidermidis strain and its adhesion-positive, accumulation-negative mutant M7. FEMS Microbiol Lett. 1994;117(1):71-8.

11. LaPlante $\mathrm{KL}$, Mermel LA. In vitro activities of telavancin and vancomycin against biofilmproducing Staphylococcus aureus, S. epidermidis, and Enterococcus faecalis strains. Antimicrob Agents Chemother. 2009;53(7):3166-9.

12. LaPlante KL, Mermel LA. In vitro activity of daptomycin and vancomycin lock solutions on staphylococcal biofilms in a central venous catheter model. Nephrol Dial Transplant. 2007;22(8):2239-46.

13. Luther MK, Arvanitis M, Mylonakis E, LaPlante KL. Activity of daptomycin or linezolid in combination with rifampin or gentamicin against biofilmforming Enterococcus faecalis or E. faecium in an in vitro pharmacodynamic model using simulated endocardial vegetations and an in vivo survival assay using Galleria mellonella larvae. Antimicrob Agents Chemother. 2014;58(8):4612-20.

14. Christensen GD, Simpson WA, Younger JJ, et al. Adherence of coagulase-negative staphylococci to plastic tissue culture plates: a quantitative model for the adherence of staphylococci to medical devices. J Clin Microbiol. 1985;22(6): 996-1006.

15. Amorena B, Gracia E, Monzon M, et al. Antibiotic susceptibility assay for Staphylococcus aureus in biofilms developed in vitro. J Antimicrob Chemother. 1999;44(1):43-55.

16. Koseki H, Yonekura A, Shida T, et al. Early staphylococcal biofilm formation on solid orthopaedic implant materials: in vitro study. PLoS One. 2014;9(10):e107588.
17. Shenep LE, Shenep MA, Cheatham W, et al. Efficacy of intravascular catheter lock solutions containing preservatives in the prevention of microbial colonization. J Hosp Infect. 2011;79(4):317-22.

18. Chambers ST, Pithie A, Gallagher K, Liu T, Charles CJ, Seaward L. Treatment of Staphylococcus epidermidis central vascular catheter infection with $70 \%$ ethanol locks: efficacy in a sheep model. J Antimicrob Chemother. 2007;59(4):779-82.

19. Chaudhury A, Rangineni J, Venkatramana B. Catheter lock technique: in vitro efficacy of ethanol for eradication of methicillin-resistant staphylococcal biofilm compared with other agents. FEMS Immunol Med Microbiol. 2012;65(2):305-8.

20. Ali Y, Dolan MJ, Fendler EJ, Larson EL. Alcohols. In: Block SS, editor. Disinfection, sterilization, and preservation. Philadelphia: Lippincott Williams \& Wilkin; 2001. p. 229-54.

21. Rutala WA, Weber DJ, Healthcare Infection Control Practices Advisory Committee (HICPAC) Guideline for Disinfection and Sterilization in Healthcare Facilities: CDC; 2008 [cited 20154 Apr]. Available from: http://www.cdc.gov/hicpac/pdf/guidelines/ Disinfection_Nov_2008.pdf.

22. Ingram LO. Ethanol tolerance in bacteria. Crit Rev Biotechnol. 1990;9(4):305-19.

23. Hussain M, Herrmann M, von Eiff C, PerdreauRemington F, Peters G. A 140-kilodalton extracellular protein is essential for the accumulation of Staphylococcus epidermidis strains on surfaces. Infect Immun. 1997;65(2):519-24.

24. Sun D, Accavitti MA, Bryers JD. Inhibition of biofilm formation by monoclonal antibodies against Staphylococcus epidermidis RP62A accumulation-associated protein. Clin Diagn Lab Immunol. 2005;12(1):93-100.

25. Adam B, Baillie GS, Douglas LJ. Mixed species biofilms of Candida albicans and Staphylococcus epidermidis. J Med Microbiol. 2002;51(4):344-9.

26. Al-Fattani MA, Douglas LJ. Biofilm matrix of Candida albicans and Candida tropicalis: chemical composition and role in drug resistance. J Med Microbiol. 2006;55(Pt 8):999-1008.

27. Al-Fattani MA, Douglas LJ. Penetration of Candida biofilms by antifungal agents. Antimicrob Agents Chemother. 2004;48(9):3291-7.

28. Schwank S, Rajacic Z, Zimmerli W, Blaser J. Impact of bacterial biofilm formation on in vitro and in vivo activities of antibiotics. Antimicrob Agents Chemother. 1998;42(4):895-8. 
29. Cue D, Lei MG, Lee CY. Genetic regulation of the intercellular adhesion locus in staphylococci. Front Cell Infect Microbiol. 2012;2:38.

30. Korem M, Gov Y, Rosenberg M. Global gene expression in Staphylococcus aureus following exposure to alcohol. Microb Pathog. 2010;48(2): 74-84.
31. Raad I, Hanna H, Dvorak T, Chaiban G, Hachem R. Optimal antimicrobial catheter lock solution, using different combinations of minocycline, EDTA, and 25-percent ethanol, rapidly eradicates organisms embedded in biofilm. Antimicrob Agents Chemother. 2007;51(1):78-83. 